\title{
Topical Application of Hesperidin, a Citrus Bioflavanone Accelerates Healing of Full Thickness Dermal Excision Wounds in Mice Exposed to 6 Gy of Whole Body $\Gamma$-Radiation
}

\author{
Ganesh Chandra Jagetia* and KVN Mallikarjuna Rao
}

Department of Zoology, Mizoram University, Tanhril, Aizawl-796 004, Mizoram, India

Received: June 01, 2017; Accepted: July 15, 2017; Published: August 20, 2017

${ }^{*}$ Corresponding author: Ganesh Chandra Jagetia, Professor, Department of Zoology, Mizoram University, Tanhril, Aizawl-796 004, Mizoram, India, Tel: 011-389-233724; Fax: 011-389-233227, E-mail: gc.jagetia@gmail.com

\begin{abstract}
The irradiation leads to delayed wound healing and the paradigms that can enhance the healing of irradiated wound will be useful, especially in conditions where wounds are exposed to ionizing radiation before or after surgery. The wound healing activity of various concentrations of hesperidin ointment was investigated in mice exposed to 6 Gy of whole body $\gamma$-radiation after infliction with a full thickness circular excision wound of $15 \mathrm{~mm}$ diameter by measuring wound contraction using videography and determining the mean wound healing time. Topical application of different concentrations of hesperidin ointment twice daily accelerated the healing of irradiated wounds in a concentration dependent fashion when compared to placebo application on the irradiated wounds. A maximum wound contraction was observed for $5 \%$ hesperidin ointment when compared to the other concentrations. Likewise, the mean wound healing time also reduced in a concentration dependent manner in the animals receiving a topical application of $5 \%$ hesperidin, where it was shorter by 2.7 days when compared to the irradiated placebo controls. The present study demonstrates that topical application of hesperidin accelerates healing of normal as well as irradiated wounds and may serve as a useful paradigm for the management of irradiated wounds in a clinical setting and after nuclear disaster. The acute toxicity determination of hesperidin showed that animals were able to tolerate $5 \mathrm{~g} / \mathrm{kg}$ body weight and it was No Observed Adverse Effect Level (NOAEL) dose. No symptoms of toxicity in any form were observed at this dose. In vitro free radical scavenging revealed that hesperidin scavenged,, DPPH, hydroxyl, superoxide, ABTS ${ }^{\bullet+}$ and Nitric oxide radical in a concentration dependent manner.
\end{abstract}

KEYWORDS: Radiation; Mice; Wound; Acute toxicity; Free radicals;

\section{Introduction}

Since the discovery of X-rays by Roentgen in the year 1895, ionizing radiations have been used for medical purposes owing to their ability to see inside the human body. It is well established that ionizing radiations produce harmful effects in the living beings. The induction of free radicals by ionization radiations is the principal cause of tissue injury in the exposed organisms [1]. These free radicals initiate a cascade of events leading damage to the cellular DNA and finally the cell death [2]. Organisms are well equipped to heal the radiation-induced damage if exposed to radiation within reasonable limits. However, it may not be possible for the organisms to effectively repair the radiation induced-damage after the breach of this limit, which can produce adverse effect on the various tissues depending on the individual sensitivity of a particular tissue. It is almost impossible to spare overlying normal skin and subcutaneous tissue from radiation exposure while delivering an appropriate radiation dose to tumor bed during radiotherapy. The damage to these structures is unfortunately irreversible and dose dependent $[3,4]$. The irradiation of skin causes erythema, desquamation, ulceration, telangiectasia, fibrosis and induction of skin carcinoma [4-7].
The acute radiation exposure associated with combined injuries in the form of superimposed skin wounds and/or burn injury, produces serious clinical problems, since ionizing radiation disrupts normal response to injury, leading to a protracted recovery period [7-10]. Irradiation has been reported to alter the local conditions of wound, resulting in a delay in wound contraction, which is non-conducive to continuance of healing process [8,11-14]. The combination of wounding and Whole Body Irradiation (WBI) has been reported to retard wound healing and the mechanisms are not fully understood $[12,13,15,16]$. The recent nuclear disaster at Fukushima and threat of nuclear warfare indicate that countermeasures are required to deal with the combined injuries in such a situation [17].

Hesperidin (hesperitin-7-rhamnoglucoside or hesperitin-7rutinoside), a predominant bioflavonoid, is found in citrus fruits, sweet oranges (Citrus sinensis) and tangelos [18,19]. Pure hesperidin occurs as long hair-like needles, tan or pale yellow in colour. Hesperidin exhibits antioxidant and anti-inflammatory properties [20-22]. It has been demonstrated to possess significant antihypertensive and diuretic effects in rats following oral administration of $200 \mathrm{mg} / \mathrm{kg}$ body weight hesperidin [20]. Hesperidin has been found to inhibit tumor initiation and promotion and reverse the neoplastic transformation of C3H10T1/2 fibroblasts [23-25]. It has also been found to reduce cholesterol levels and retard bone loss in humans [26,27]. Deficiency of hesperidin has been indicated in abnormal capillary leakage. Hesperidin has been found to possess beneficial effects on the abnormal capillary permeability, fragility and protection against various traumas and stresses [28]. Hesperidin has been found to protect against pulmonary fibrosis, cisplatin-induced nephrotoxicity and glucocorticoids-induced skin toxicity [29-31]. It has also been reported to be radioprotective in vitro and in vivo $[32,33]$. The effect of topical application of hesperidin has not been studied; therefore the present study was undertaken to obtain an insight into the effect of topical application of hesperidin ointment on wound healing in mice whole body exposed to 6 Gy-radiation.

\section{Materials and Methods}

\section{Chemicals and Drugs}

Hesperidin was obtained from Acros Organics Ltd, Geel, Belgium. Deoxyribose, Nitro Blue Tetrazolium (NBT), 1, 1- diphenyl-2-picryl hydrazyl, 2, 2- azinobis (3-ethyl benzothiazoline - 6-sulphonic acid) diammonium salt, sodium nitroprusside, Napthyl Ethylenediamine Dihydrochloride (NED) and ethylenediaminetetraacetic acid (EDTA) were procured from Sigma Chemicals Co. St. Louis, USA. Potassium hydrogen phosphate, sodium hydroxide, ferric chloride, hydrogen peroxide, ascorbic acid, dimethylsulfoxide and other routine chemicals were supplied by Merck India, Mumbai. 


\section{Animal care and Handling}

The animal care and handling were carried out according to the guidelines of World Health Organization, Geneva, Switzerland and the INSA (Indian National Science Academy, New Delhi). Eight to ten week old Swiss albino mice of either sex weighing 30 to $36 \mathrm{~g}$ were selected from an inbred colony maintained under the controlled conditions of temperature $\left(23 \pm 2^{\circ} \mathrm{C}\right)$, humidity $(50 \pm 5 \%)$ and light $(12$ hours of light and dark, respectively). The animals had free access to sterile food and water. The food consisted of 50\% cracked wheat, $40 \%$ Bengal gram, $4 \%$ milk powder, $4 \%$ yeast powder, $0.75 \%$ sesame oil, $0.25 \%$ cod liver oil and $1 \%$ salt. Usually four animal were housed in a polypropylene cage containing sterile paddy husk (procured locally) as bedding throughout the experiments. The study was approved by the institutional animal ethical committee.

\section{Experimental}

\section{Determination of acute toxicity}

The acute toxicity of hesperidin was determined as described earlier $[34,35]$. Briefly, the animals were allowed to fast $18 \mathrm{~h}$ by withdrawing food and water. The fasted animals were divided into several groups of 10 each. Each group of animals was orally administered with $0,500,1000$ 2000,4000 and $5000 \mathrm{mg} / \mathrm{kg} \mathrm{b}$. wt. of hesperidin freshly prepared in $1 \%$ carboxymethyl cellulose. The animals were provided with food and water immediately after the drug administration. Survival of the animals was monitored up to 14 days post drug treatment. A minimum of ten animals was used for each drug dose.

\section{Preparation of ointment and Mode of Administration}

Different concentrations viz: $1,2,5$ or $10 \%$ of hesperidin ointment were prepared using standard procedures. Each wound received an amount of 2, 4, 10 or $20 \mathrm{mg}$ hesperidin with single application depending on the concentration applied. The animals received topical application of various concentrations of hesperidin ointment twice a day until complete healing of wounds. The first application was done at $3 \mathrm{~h}$ after creation of the wounds and a gap of $8 \mathrm{~h}$ was always allowed between first and second applications. The ointment base is referred as ONT whereas hesperidin ointment as HPD hereafter.

\section{Effect of various concentrations of hesperidin ointment on wound contraction}

To study the effect of topical application of hesperidin ointment on irradiated wounds, the animals were divided into following groups:

ONT+sham-irradiation: The animals of this group received only ointment base topically on the wound twice a day so as to cover the area of whole excision wounds, until complete healing of wounds after shamirradiation (0 Gy).

HPD+ sham-irradiation: The animals of this group were topically applied twice a day with 1, 2, 5 or $10 \%$ of hesperidin ointment in such a way so as to cover the whole excision wound, until complete healing of wounds after sham-irradiation (0 Gy).

ONT+ irradiation: The animals of this group received only ointment base after exposure to 6 Gy radiation in a similar fashion as described for ONT+sham-irradiation group.

HPD+ irradiation: This group of animals received 1, 2, 5 or $10 \%$ of hesperidin ointment topically covering the whole excision wounds, twice daily after exposure to $6 \mathrm{~Gy} \gamma$-radiation until complete healing of wounds.

\section{Irradiation}

Each prostate animal was placed into a specially designed wellventilated acrylic restrainer and whole-body of the animal was exposed to 0 or $6 \mathrm{~Gy}$, delivered at a dose rate of $1.35 \mathrm{~Gy} / \mathrm{min}$ from a ${ }^{60} \mathrm{Co}$ Teletherapy source (Theratron, Atomic Energy Agency, Ontario, Canada) at the SSD of $80 \mathrm{~cm}$ and a field size of $20 \times 20 \mathrm{cms}$.

\section{Production of full-thickness skin wound}

The hairs of the dorsum of each animal were depilated with a cordless electric mouse clipper (Wahl Clipper Corporation, Illinois, USA) before exposure to $\gamma$ radiation and a full-thickness skin wound was produced on the dorsum (below the rib cage) after $10 \mathrm{~min}$ of irradiation [12-14]. Briefly, the animals were anesthetized using ketamine and the entire body was cleaned and decontaminated by wiping with sterillium (Bode Chemical Company, Hamburg, Germany) disinfectant solution. The cleared dorsal surface of skin was marked with a sterile circular (15-mmdiameter) stainless steel stencil. A full-thickness deep dermal wound was created by excising the skin including panniculus carnosus in an aseptic environment using sterile scissors and forceps. Each wounded animal was housed in a separate sterile polypropylene cage and monitored until complete healing of the wounds.

\section{Measurement of wound contraction}

Wound contraction was assessed by capturing the video images of each full-thickness wound with a CCD camera connected to a computer. The first image of each wound from different groups was captured on the day of wounding, and that day was considered as day one. The subsequent images were acquired on day 3, 6, 9, 12 and 15 post-wounding. The wound area was calculated using Auto CAD R14 (Autodesk Inc., San Rafael, CA) software. Eight animals were used in each group for each HPD dose.

\section{Mean wound healing time}

A separate experiment was conducted to evaluate the effect of hesperidin on Mean Healing Time (MHT) after exposure to 0 or 6 Gy whole-body $\gamma$-radiation, where groups and other conditions remained essentially similar to that described above, except that no attempt was made to capture the video images after wounding. All animals of each group were monitored until complete healing of wounds and the day at which each wound healed was recorded. Mean of all healed wounds was determined and has been expressed as Mean wound Healing Time (MHT) in days. Eight animals were used in each group for each HPD dose.

\section{Estimation of free radical scavenging in vitro}

The ability of hesperidin to scavenge different free radicals in vitro was determined as follow:-

\section{Hydroxyl radical scavenging activity}

The scavenging of hydroxyl $(\mathrm{OH})$ free radical was measured by the method described earlier [36]. Briefly, the reaction mixture contained deoxyribose (2.8 mM), $\mathrm{KH}_{2} \mathrm{PO}_{4}-\mathrm{NaOH}$ buffer, $\mathrm{pH} 7.4(0.05 \mathrm{M}), \mathrm{FeCl}_{3}(0.1$ $\mathrm{mM})$, EDTA (0.1 mM), $\mathrm{H}_{2} \mathrm{O}_{2}(1 \mathrm{mM})$, ascorbate $(0.1 \mathrm{mM})$ and $\mathrm{HPD}(20,40$, $60,80,100,200,300,400,500$ and $600 \mu \mathrm{g} / \mathrm{ml}$ ) in a final volume of $2 \mathrm{ml}$. The reaction mixture was incubated for $30 \mathrm{~min}$ at ambient temperature followed by the addition of $2 \mathrm{ml}$ of trichloroacetic acid (2.8\% W/V) and thiobarbituric acid. The reaction mixture was kept in a boiling water bath for $30 \mathrm{~min}$, cooled and the absorbance was read at $532 \mathrm{~nm}$ in a UV-VIS double beam spectrophotometer (UV-260, Shimadzu Corp, Japan).

\section{Superoxide anion scavenging activity}

The scavenging of superoxide $\left(\mathrm{O}_{2}^{-}\right)$anion radical was measured as described earlier [37]. Briefly, the reaction mixture consisted of various concentrations of HPD $(20,40,60,80,100,200,300,400,500$ and 600 $\mu \mathrm{g} / \mathrm{ml}$ ), nitroblue tetrazolium, and alkaline DMSO. The blank consisted of pure DMSO instead of alkaline DMSO. The absorbance was read at $560 \mathrm{~nm}$ using a UV-Visible double beam spectrophotometer (UV-260, Shimadzu Corp, Japan).

\section{DPPH scavenging activity}

The principle for the reduction of 1,1- diphenyl-2-picryl hydrazyl (DPPH) free radical is that, the antioxidant reacts with stable free radical, DPPH and converts it into 1, 1-diphenyl -2-picryl hydrazine. The ability to scavenge the stable free radical DPPH is measured by decrease in the absorbance at $517 \mathrm{~nm}$ [38]. To the ethanolic solution of DPPH $(0.05 \mathrm{mM})$, an equal volume of $\operatorname{HPD}(20,40,60,80,100,200,300,400,500$ and 600 $\mu \mathrm{g} / \mathrm{ml}$ ) dissolved in water, was added to a final volume of $1.0 \mathrm{ml}$. An equal amount of methanol was added to the control. After $20 \mathrm{~min}$, absorbance was recorded at $517 \mathrm{~nm}$ in a UV-Visible double beam spectrophotometer (UV-260, Shimadzu Corp, Japan). 


\section{Total antioxidant activity assay}

Total antioxidant potential was determined by ABTS (2, 2- azinobis (3-ethyl benzothiazoline - 6-sulphonic acid) diammonium salt) assay [39]. This technique measures the relative ability of antioxidant substances to scavenge the ABTS cation radical generated in the aqueous phase. The reaction mixture contained ABTS $(0.00017 \mathrm{M}), \operatorname{HPD}(20,40,60,80,100$ $200,300,400,500$ and $600 \mu \mathrm{g} / \mathrm{ml}$ ), and buffer in a total volume of $3.5 \mathrm{ml}$ The absorbance was measured at $734 \mathrm{~nm}$ using a UV-Visible double beam spectrophotometer (UV-260, Shimadzu Corp, Japan).

\section{Nitric oxide scavenging activity}

Nitric oxide was generated from sodium nitroprusside and measured by the Griess reaction as described previously. Sodium nitroprusside in aqueous solution at physiological $\mathrm{pH}$ spontaneously generates nitric oxide which interacts with oxygen to produce nitrite ions that can be estimated by use of Griess reagent [40]. Scavengers of nitric oxide compete with oxygen leading to reduced production of nitric oxide [40]. Sodium nitroprusside $(5 \mathrm{mM})$ in phosphate-buffered saline was mixed with different concentrations of HPD (20,40, 60, 80, 100, 200, 300, 400, 500 and $600 \mu \mathrm{g} / \mathrm{ml}$ ) and incubated at $25^{\circ} \mathrm{C}$ for $150 \mathrm{~min}$. The samples from the above were reacted with Greiss reagent (1\% sulphanilamide, $2 \% \mathrm{H}_{3} \mathrm{PO}$ and $0.1 \%$ napthylethylenediamine dihydrochloride). The absorbance of the chromaphore formed during the diazotization of nitrite with sulphanilamide and subsequent coupling with napthylethylenediamine was read at $546 \mathrm{~nm}$ and referred to the absorbance of standard solutions of potassium nitrite treated in the same way with Griess reagent.

\section{Analysis of Data}

Statistical significance between the treatments was determined using one way ANOVA. The Solo 4 Statistical Package (BMDP Statistical Software Inc., Los Angles, CA, and USA) was used for data analysis. All data are expressed as mean \pm SEM (Standard error of mean).

\section{Results}

\section{Acute toxicity}

Oral administration of $0,500,1000,2000,4000$ and $5000 \mathrm{mg} / \mathrm{kg} \mathrm{b}$. wt. of hesperidin did not induce any adverse effect on the body weights and general health of the animals. Not a single animal died during the whole observation period. Due to experimental constraints such as drug dissolution it was not possible to test higher doses of hesperidin for acute toxicity studies. Therefore it was concluded that hesperidin is safe up to a dose of $5000 \mathrm{mg} / \mathrm{kg} \mathrm{b}$. wt. in mice, when given orally as this dose did not produce any adverse effect in the form of weight loss, debility, neurological disorders and death.

\section{Effect of various doses of hesperidin ointment on wound contraction}

Initially a separate experiment was conducted to investigate the effect of single topical application of different concentration of hesperidin ointment on irradiated wounds. However, single application did not improve the healing of irradiated wounds and therefore studies in this direction were not pursued further and experiments were redesigned to study the effect of two applications of hesperidin and the results of these experiments are presented below.

Treatment of mice with ONT or various concentrations of hesperidin ointment resulted in a steady contraction of excision wounds with time in ONT+sham-irradiation and HPD+ sham-irradiation groups (0 Gy). The topical application of $1,2,5$ or $10 \%$ of hesperidin ointment twice daily enhanced the wound contraction in a concentration dependent manner at various post-irradiation times and a significant enhancement of wound contraction was observed only after application of $5 \%$ hesperidin ointment, when compared with ONT+ sham-irradiation group at $3(\mathrm{p}<$ $0.05), 6(\mathrm{p}<0.005), 9(\mathrm{p}<0.005)$ and $12(\mathrm{p}<0.05)$ post-irradiation days. Similarly, application of hesperidin ointment also showed a progressive reduction in the scab formation with increasing concentration of HPD, and it was almost absent for $5 \%$ hesperidin ointment.
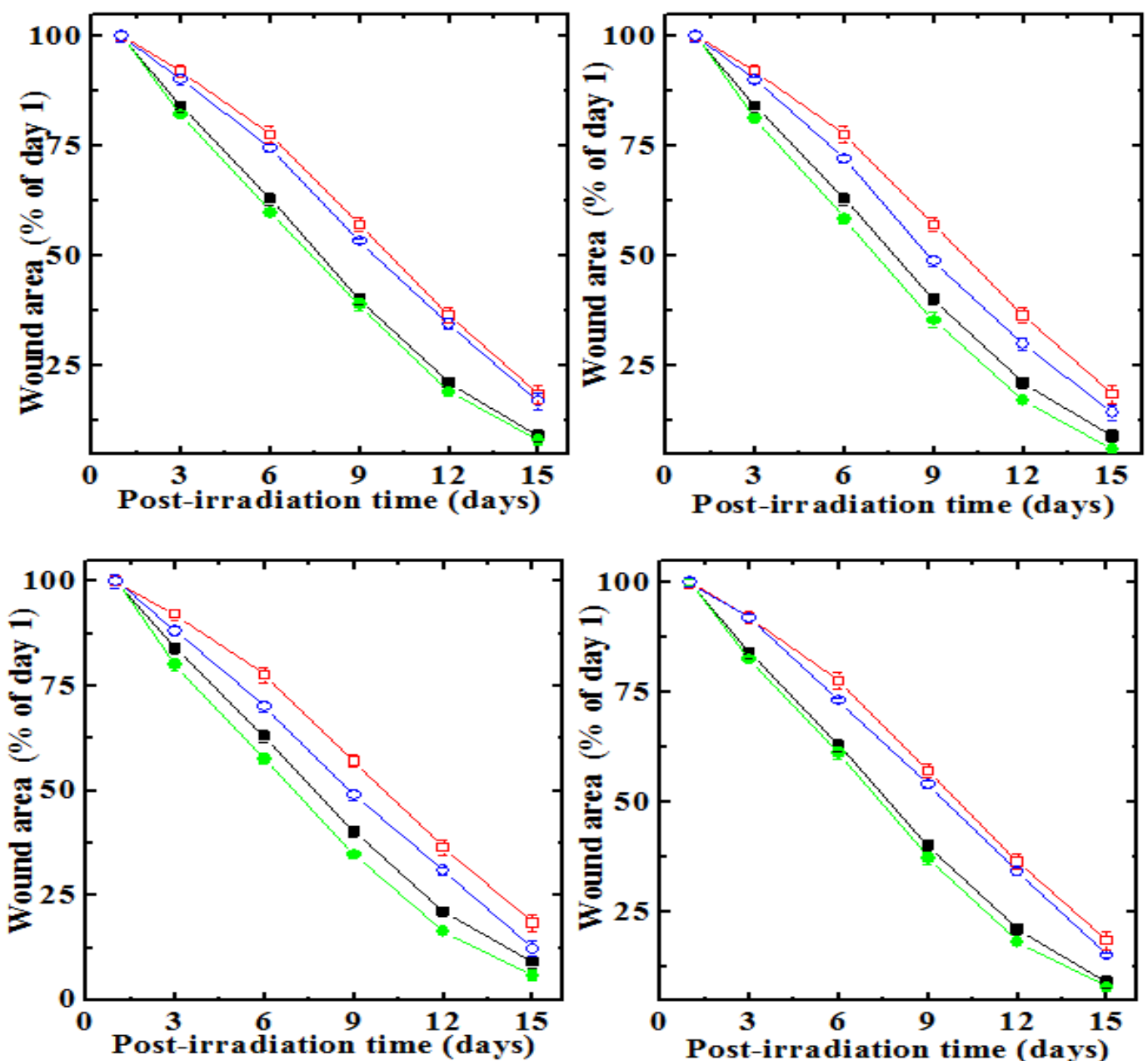

Figure 1: CEffect of various concentrations of topical application of hesperidin on the contraction of excision wound in mice exposed to 6 Gy whole-body $\gamma$-radiations. Upper left: 1\%; Upper right: 2\%; Lower left:: $5 \%$ and Lower right: 10\% of hesperidin applied twice daily on deep dermal excision wounds. Closed squares: Ointment +sham-irradiation; Closed circles: Hesperidin+sham-irradiation; Open squares Ointment + irradiation and Open circles: Hesperidin+irradiation. 
The whole body irradiation of animals to 6 Gy caused a thick scab formation in ONT+irradiation group accompanied by a significant retardation in wound contraction when compared with ONT+ shamirradiation group at all post-irradiation days. Use of various doses of HPD ointment topically increased the wound contraction and a significant rise in wound contraction was observed after application of $5 \%$ hesperidin ointment at 3, 6, 9 and 12 day post-irradiation (Figure 1c). The application of $10 \%$ hesperidin ointment also accelerated wound contraction however the difference between the $\mathrm{CMC}+$ irradiation and $\mathrm{HPD}+$ irradiation groups were statistically non-significant. Topical application of various doses of hesperidin ointment on the excision wounds caused thin scab formation and early fall of scab. The scab formation was altogether absent in the group of animals applied with $5 \%$ hesperidin ointment twice daily after 6 Gy irradiation until complete healing of wounds.

\section{Effect of various doses of hesperidin ointment on wound contraction}

The complete closure of wounds was observed by 19.32 day postirradiation in placebo control (ONT+sham-irradiation) group. Whereas topical application of $1 \%$ and $2 \%$ hesperidin ointment did not alter the mean wound healing time significantly when compared with the ONT+ sham-irradiation group. However when hesperidin concentration was raised to $5 \%$ in the ointment it reduced the MHT by almost 3 days with a MHT of 16.2 days. A further increase in hesperidin concentration to $10 \%$ did not alter the MHT significantly (Figure 2).

The whole-body exposure of mice to 6 Gy $\gamma$-radiation resulted in a significant delay in the complete closure of wounds as a result, the MHT was also delayed by 4 days and a complete wound closure was achieved by day 23.62 post-irradiation in ONT+irradiation group when compared with the ONT+sham-irradiation group. The topical application of animals with $5 \%$ hesperidin ointment resulted in an early healing of wound and the complete healing of wound was effected by 20.94 day post-irradiation when compared with ONT+irradiation group, whereas 1,2 or $10 \%$ hesperidin ointment did not significantly reduce the mean wound healing time in comparison with ONT+irradiation group (Figure 2).

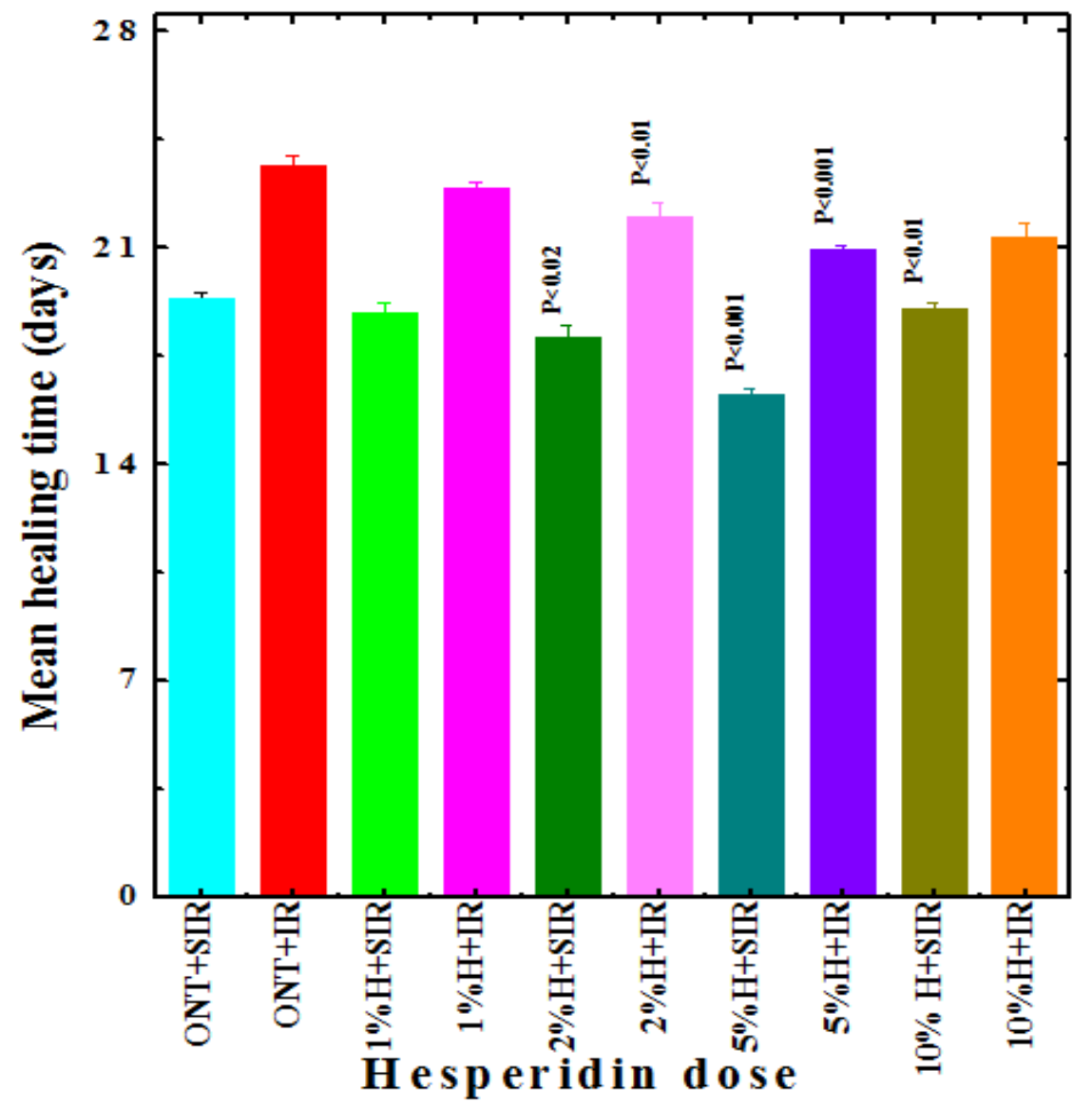

Figure 2: Effect of topical application of various concentrations of hesperidin on the mean wound healing time in mice exposed to 6 Gy whole-body $\gamma$-ra-diations. $p<0.05$ when Ointment (ONT) groups are compared to hesperidin groups. SIR: Sham-irradiation; H: Hesperidin and IR: irradiation.

\section{Free radical scavenging}

The data are shown as percent inhibition of free radical generation in (Figure 3). The HPD inhibited the generation of ${ }^{\bullet} \mathrm{OH}$ and $\mathrm{O}_{2}{ }^{\bullet}$ radicals in a concentration dependent manner and a maximum scavenging was observed at $500 \mu \mathrm{g} / \mathrm{ml}$ (Figure $3 \mathrm{a}, \mathrm{b}$ ). The HPD was ineffective in scavenging DPPH radical up to a concentration of $100 \mu \mathrm{g} / \mathrm{ml}$, however, a further increase in HPD concentration resulted in a concentration dependent elevation in DPPH scavenging up to $500 \mu \mathrm{g} / \mathrm{ml}$ (Figure 3c). The total antioxidant activity was measured using ABTS assay and the inhibition of $\mathrm{ABTS}^{\bullet+}$ radicals showed a concentration dependent scavenging up to $200 \mu \mathrm{g} / \mathrm{ml}$ and plateaued thereafter (Figure 3d). The HPD also showed a dose dependent scavenging of nitric oxide up to $60 \mu \mathrm{g} / \mathrm{ml}$ thereafter, the elevation of nitric oxide scavenging reached an almost steady state. However, the maximum scavenging of nitric oxide was observed at 400 $\mu \mathrm{g} / \mathrm{ml}$ (Figure 3e).

\section{Discussion}

Flavonoids comprise a large group of naturally occurring; low molecular weight ployphenolic compounds that are widely synthesized by plants as secondary metabolites. Flavonoids occur in practically all parts of branched plants including fruit, vegetables, nuts, seeds, leaves, flowers, and bark [41,42]. The flavanones are found abundantly in citrus fruits $[18,43]$. Flavonoids have been reported to have several beneficial effects on human health [44]. Hesperidin is one such flavanone, which has been reported to be an antioxidant, anti-inflammatory, and anticarcinogenic $[27,45]$. The ionizing radiations produce adverse health effects and it is necessary to devise countermeasures against the combined injuries as defence preparedness, especially during nuclear disasters, nuclear warfare and the terror attacks. The effect of topical application of hesperidin in combination with radiation in healing of excision wounds has not been investigated. Therefore, the present study was undertaken to evaluate the effect of topical application of hesperidin in healing of excision wounds of mice whole body exposed to 6 Gy of $\gamma$-radiation.

Wound contraction can be defined as the centripetal movement of the edges of a full thickness wound in order to facilitate closure of the defect [46]. The morphologically wound healing progress can be monitored by the periodic evaluation of contraction of excision wounds using various methods and videography of wound allows measurement of healing [10]. Whole body irradiation of mice to 6 Gy caused a significant retardation in wound contraction leading to an increase in the wound healing time significantly in mice. This is in conformation with earlier studies, where a similar effect has been reported $[8,12-14,16,47]$. This may be due to several possible reasons including inhibition of inflammatory reactions, fibroblast and connective tissue proliferation, formation and maturation of granulation tissue after irradiation $[4,9,48]$. The neutrophils and macrophages play an important role by generation of $\mathrm{H}_{2} \mathrm{O}_{2}$ at the wound site and thereby adding in healing of wounds [49]. However, irradiation kills these cells reducing the inflammatory response and delaying the wound healing. The proinflammatory cytokine TNF $\alpha$ has been reported to play an important role in wound healing [50] and its over production by radiation may have negative effect on wound healing leading to delayed wound healing [51].

The major impact of irradiation is to reduce the cell proliferation, which leads into delay in fixation of wound edge to the underlying tissue owing to a lack of fibroblast proliferation and a decrease in fibroblast synthetic function in the granulation bed. Further, wound contraction of open excision wounds has been found to be a function of contractile fibroblasts, known as myofibroblasts [52,53] that are adversely affected by irradiation as ionizing radiations produce cytotoxic effect on fibroblasts and impair wound healing [14,54]. The killing of fibroblasts, known as myofibroblasts will also have negative effect on extracellular matrix deposition impairing the wound healing. This impairment may be as a result of delay in the progression of cells through various phases of cell cycle induced by radiation $[48,55]$. The fibroblasts also secrete different angiogenic factors including VEGF, transforming growth factor- $\beta$ (TGF- $\beta$ ) and Platelet Derived Growth Factor (PDGF), which are the involved in the formation of new blood vessels during tissue repair [56] and irradiation will negatively affect these processes due fibroblast killing [47]. Radiation has been found to adversely affect the fibroblasts and endothelial cells 

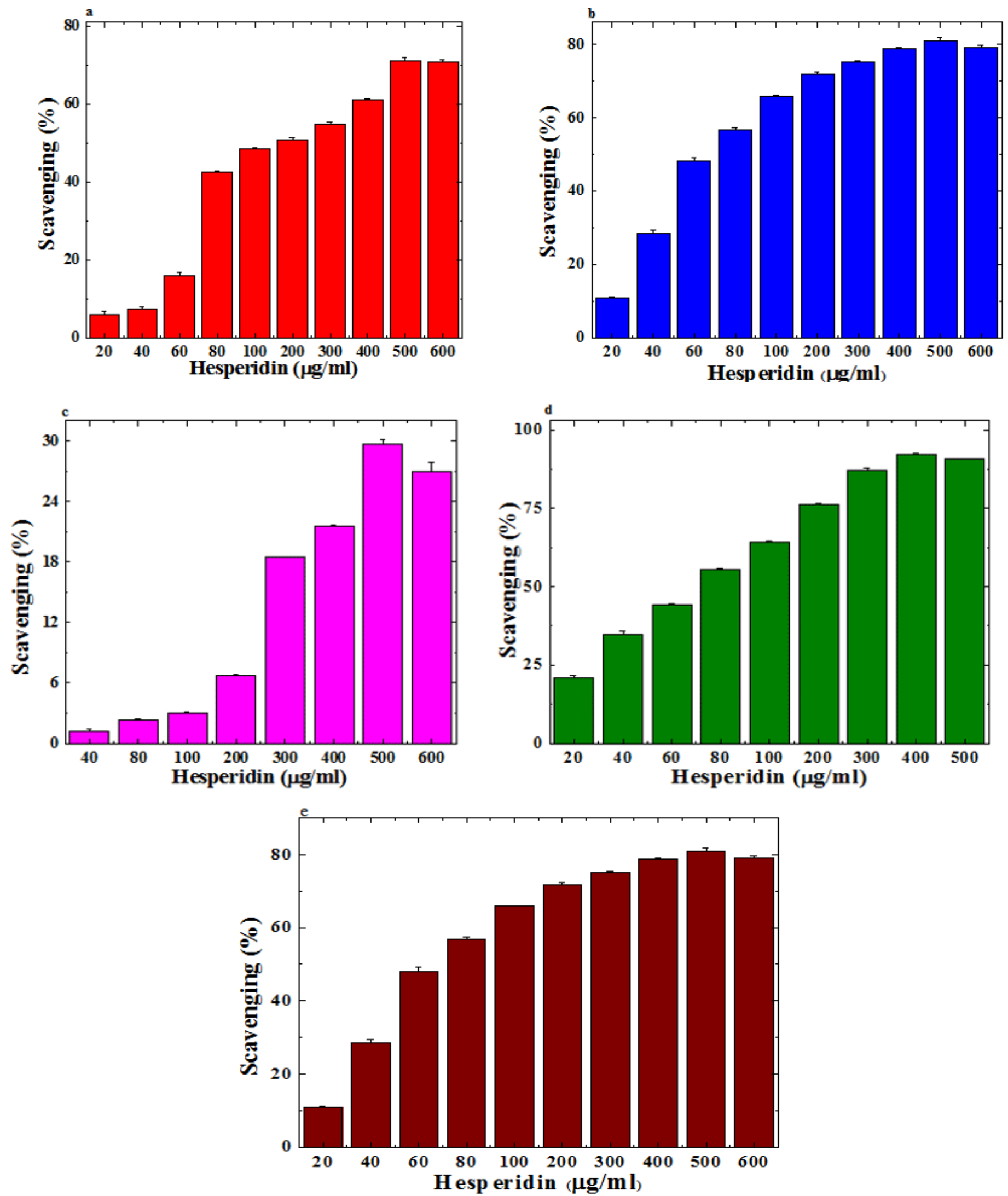

Figure 3: Effect of various concentrations of hesperidin on the scavenging of various free radicals and ABTS ${ }^{\bullet+}$ cation radical. a) Hydroxyl radical; b) Superoxide anion, c) DPPH radical d) ABTS $^{\bullet+}$ cation radical and e) Nitric oxide.

due to bone marrow depression and in fact radiation has been reported to diminish hematopoiesis in a dose- and time-dependent manner [14, 5759]. A similar effect cannot be ruled out in the present study where whole body of the animal has been irradiated during the exposure.

Effect of hesperidin on irradiated wound has not been evaluated and it is probably the first report where topical application of various concentrations of hesperidin ointment on the irradiated wounds twice daily has accelerated the healing of irradiated wounds when compared to irradiated controls that received application of ointment base only. This was evident by early contraction and closure of wounds by $5 \%$ hesperidin ointment and a further increase in dose did not increase the effect which could be due to the fact that $5 \%$ hesperidin has accelerated the wound healing to maximum extent and increase thereafter could not stimulate the fibroblasts and other factors responsible for wound healing. Similarly, topical application of curcumin ointment has been reported to accelerate the healing of irradiated excision wound recently [60]. The ascorbic acid and curcumin have been reported to accelerate healing of wounds in mice exposed to whole body $\gamma$-radiation $[12,14,61,62]$. The extract of Nigella sativa has been also reported to enhance the healing of irradiated wound recently [47]. Phenytoin has been reported to accelerate wound healing in humans [63]. 
The exact mechanism of acceleration in wound healing by hesperidin is not clear. However, it may have acted using multiple pathways to increase the healing of wounds after whole body irradiation. Application of hesperidin ointment may have scavenged the excess free radicals induced by irradiation and wounding and thus helped in accelerated repair of wound injury. We have observed scavenging of various free radicals in the present study. Increase in antioxidant status by hesperidin has been found to scavenge free radicals [64]. Wounding and irradiation has been reported to induce transcriptional activation of NF-кB, COX-II and LOX causing adverse impact on the healing of irradiated wounds $[4,65,66]$. Application of hesperidin may have inhibited the transcriptional activation of NF-кB, COX-II and LOX and restored normal regenerative capacity of irradiated wounds. Hesperidin has been reported to inhibit the activation of NF$\mathrm{\kappa B}$, and COX-II earlier [67,68]. Further, irradiation reduces antioxidants and thus delay normal healing of wounds $[22,47,69]$. The restoration of antioxidants by hesperidin may have also played a significant role in the accelerated recovery of irradiated wounds. In fact hesperidin has been reported to elevate antioxidant status in the skin of irradiated mice earlier [22]. This increase in antioxidant status by hesperidin may be due to the transcriptional activation of Nrf2 pathways [70].

\section{Conclusions}

Topical application of hesperidin in ointment base increased the regenerating capacity of irradiated wounds, if applied twice daily and it also helped to accelerated wound repair and regeneration in nonirradiated wounds. The observed effect may be due scavenging of radiation and injury-induced free radicals, increased antioxidant status by stimulating the Nrf2 pathways and inhibition of NF- $\mathrm{KB}$ and COX-II. Hesperidin, bioflavonoid found in citrus fruits, that are consumed daily by humans could be useful paradigm to heal the normal and irradiated wounds.

\section{Acknowledgements}

The authors are thankful to Dr. M.S. Vidyasagar, Professor and Head, and Dr. J.G.R. Solomon, Department of Radiotherapy and Oncology, Kasturba Medical College Hospital, Manipal, India for providing the necessary irradiation facilities and dosimetric calculations, respectively. The authors wish to acknowledge the financial support from the Defence Research and Development Organization, Ministry of Defence, Government of India and Indian Council of Medical Research, Government of India New Delhi for the financial support to carry out this study.

\section{References}

1. Azzam EI, Jay-Gerin JP, Pain D. Ionizing radiation-induced metabolic oxidative stress and prolonged cell injury. Cancer Lett. 2012;327(12):48-60. doi: 10.1016/j.canlet.2011.12.012.

2. Lomax ME, Folkes LK, O'Neill P. Biological consequences of radiationinduced DNA damage: relevance to radiotherapy. Clin Oncol. (R Coll Radiol). 2013;25(10):578-585. doi: 10.1016/j.clon.2013.06.007.

3. Bullough WS, Laurence EB. The control of epidermal mitotic activity in the mouse. Proc Roy Soc Bull. 1960;151:517-536.

4. Ryan JL. Ionizing radiation: the good, the bad, and the ugly. J Invest Dermatol. 2012;132(3 Pt 2):985-993. doi:10.1038/jid.2011.41.

5. Davis RK, Stoker K, Harker G, Davis K, Gibbs F A, Harnsberger H $\mathrm{R}$, et al. Prognostic indicators in head and neck cancer patients receiving combined therapy. Arch Otolaryngol Head Neck Surg 1989;115(12):1443-1446.

6. Turesson I, Thames HD. Repair capacity and kinetics of human skin during fractionated radiotherapy: erythema, desquamation, and telangiectasia after 3 and 5 years follow-up. Radiother Oncol. 1989;15(2):169-188.

7. Bernstein EF, Sullivan FJ, Mitchell JB. Biology of chronic radiation effect on tissues and wound healing. Clin Plast Surg. 1993;20:435-453.

8. Kumar P, Jagetia G C. Modulation of wound healing in Swiss albino mice by different doses of gamma radiation. Burns. 1995;21:163-165.

9. Gu Q, Wang D, Cui C, Gao Y, Xia G, Cui X. Effects of radiation on wound healing. J Environ Pathol Toxicol Oncol. 1998;17(2):117-123.

10.Jagetia GC, Rajanikant GK. Acceleration of wound repair by curcumin in the excision wound of mice exposed to different doses of fractionated $\gamma$-radiation. Int Wound J. 2012;9(1):76-92. doi:10.1111/j.1742481X.2011.00848.x.

11.Grillo HC, Potsaid MS. Studies on wound healing-IV, retardation of contraction by local X-irradiation and observations relating to the origin of fibroblast in repair. Ann Surg. 1961;154:741-750.

12.Jagetia GC, Rajanikant GK, Rao KVNM. Modulation of radiation-induced delay in the wound healing by ascorbic acid in mice exposed to different doses of hemi-body $\gamma$-radiation. Wounds. 2003;15(11):324-338.

13.Jagetia GC, Rajanikant GK. Curcumin treatment enhances the repair and regeneration of wounds in mice hemi-body exposed to $\gamma$-radiation. Plastic Reconstruct Surg. 2005;115(2):515-528.

14.Jagetia GC, Rajanikant GK, Rao KVNM. Ascorbic acid increases healing of excision wounds of mice whole body exposed to different doses of $\gamma$-radiation. Burns. 2007;33(4):484-494.

15.Qu JF, Cheng TM, Ran XZ. Radiation and impaired wound healing. Chin J Radiol Med Prot. 2002;22:195-197.

16.Ran XZ, Cheng TM, Lin Y, TY Xiao, Qu JF, Chen XH. Morphological study on healing of cutaneous wound combined with radiation -trauma injury in rats. Acta Acad Med Milit Tert. 2003;25:1233-1236.

17.Coleman CN, Lurie N. Lurie, Emergency medical preparedness for radiological/nuclear incidents in the United States. J Radiol Prot. 2012;32(1):N27-32. doi: 10.1088/0952-4746/32/1/N27

18. Kanes K, Tisserat B, Berhow M, Vandercook C. Phenolic composition of various tissues of Rutaceae species. Phytochemistry. 1993;32(4):967974.

19.Emim JA, Oliveria AB, Lapa AJ. Pharmacological evaluation of the anti-inflammatory activity of a citrus bioflavonoid, hesperidin and the isoflavanoids duartin and claussequinone, in rats and mice. J Pharm Pharmacol. 1994;46(2):118-122.

20.Galati EM, Monforte MT, Kirijavainen S, Forestieri AM, Trovoto A, Tripodo MM. Biological effects of hesperidin, a citrus flavonoid (note 1): anti-inflammatory and analgesic activity. Framco. 1994;40(11):709712.

21.Garg A, Garg S, Zaneveld LJ, Singla AK. Chemistry and pharmacology of the citrus bioflavonoid hesperidin. Phytother Res. 2001;15(8):655669.

22.Jagetia GC, Rao KVNM. Hesperidin, A citrus bioflavonoid reduces the oxidative stress in the skin of mouse exposed to partial body $\gamma$-radiation. Transcriptomics. 2015;3(2).

23.Berkarda B, Koyuncu H, Soybir G, Baykut F. Inhibitory effect of hesperidin on tumor initiation and promotion in mouse skin. Res Exp Med. 1998;198(2):93-99.

24.Tanaka T, Makita H, Kawabata K, Mori H, Kakumoto M, Satoh K, et al. Modulation of N-methyl- $\mathrm{N}$-amylnitrosamine - induced rat oesophageal tumourigenesis by dietary feeding diosmin and hesperidin, both alone and in combination. Carcinogenesis. 1997;18(4):761-769.

25.Franke AA, Cooney RV, Custer LJ, Mordan LJ, Tanaka Y. Inhibition of neoplastic transformation and bioavailability of dietary flavonoid agents. Adv Exp Med Biol. 1998;439:237-248.

26.Kurowska EM, Spence JD, Jordan J, Wetmore S, Freeman DJ, Piche LA, et al. HDL-cholesterol-raising effect of orange juice in subjects with hypercholesterolemia. Am J Clin Nutr. 2000;72(5):1095-1100.

27.Chiba H, Uehara M, Wu J, Wang X, Masuyama R, Suzuki K, Kanazawa K, et al. Hesperidin, a citrus flavonoid, inhibits bone loss and decrease serum and hepatic lipids in ovariectomized mice. J Nutr. 2003;133(6):18921897.

28.So FV, Guthrie N, Chambers AF, Moussa M, Carroll KK. Inhibition of Human Breast cancer cell proliferation and delay of mammary tumorigenisis by flavonoides and citrus juices. Nutr Cancer. 
1996;26(2);167-181.

29.Adikay S, Spandana U, Bharathi K. Effect of hesperidin isolated from orange peels on cisplatin-induced nephrotoxicity. Int J Pharmacog Phytochem Res. 2012;4(2):49-53.

30.Man G, Mauro TM, Kim PL, Hupe M, Zhai Y, Sun R, et al. Topical hesperidin prevents glucocorticoid-induced abnormalities in epidermal barrier function in murine skin. Exp Dermatol. 2014;23(9):645-651. doi: $10.1111 /$ exd. 12480

31.Görmeli CA, Saraç K, Çiftçi O, Timurkaan N, Malkoç S. The effects of hesperidin on idiopathic pulmonary fibrosis evaluated by histopathological-biochemical and microcomputed tomography examinations in a bleomycin-rat model. Biomed Res. 2016;27(3):737742.

32.Kalpana KB, Devipriya N, Srinivasan M, Menon VP. Investigation of the radioprotective efficacy of hesperidin against gamma-radiation induced cellular damage in cultured human peripheral blood lymphocytes. Mutat Res. 2009;676(1-2):54-61. doi: 10.1016/j.mrgentox.2009.03.005

33.Pradeep K, Ko KC, Choi MH, Kang JA, Chung YJ, Park SH. Protective effect of hesperidin, a citrus flavanoglycone, against $\gamma$-radiation-induced tissue damage in Sprague-Dawley rats. J Med Food. 2012;15(5):419427. doi: 10.1089/jmf.2011.1737

34.Prieur DJ, Young DM, Davis RD, Cooney DA, Homan ER, Dixon RL, et al. Procedures for preclinical toxicologic evaluation of cancer chemotherapeutic agents: protocols of the laboratory of toxicology. Cancer Chemother Rep 3. 1973;4(1):1-39.

35.Ghosh MN. Fundamentals of experimental pharmacology. 2nd ed. Toxicity studies. Ghosh MN,editor. Calcutta:Scientific Book Agency;1984. $153-158$

36. Halliwell B, Gutteridge JM, Aruoma OI. The deoxyribose method: a simple "test-tube" assay for determination of rate constants for reactions of hydroxyl radicals. Anal Biochem. 1987;165(1):215-219.

37.Hyland K, Voisin E, Banoun H, Auclair C. Superoxide dismutase assay using alkaline dimethylsulfoxide as superoxide anion-generating system. Anal Biochem. 1983;135(2):280-287.

38.Mensor LL, Menezes FS, Leitão GG, Reis AS, dos Santos TC, Coube CS, et al. Screening of Brazilian plant extracts for antioxidant activity by the use of DPPH free radical method. Phytother Res. 2001;15(2):127-130.

39.Miller NJ, Castelluccio C, Tijburg L, Rice-Evans C. The antioxidant properties of theaflavins and their gallate esters-radical scavengers or metal chelators? FEBS Lett. 1996;392(1):40-44.

40.Marcocci L, Packer L, Droy-Lefaix MT, Sekaki A, Gardès-Albert M. Gardes-Albert, Antioxidant action of Ginkgo biloba extract EGB 761. Methods Enzymol. 1994;234:462-475.

41.Middleton EJ. The flavonoids. Trends Pharmacol Sci. 1984;8:335-338.

42.Hollman PC, Cassidy A, Comte B, Heinonen M, Richelle M, Richling E, et al. Vidry, The biological relevance of direct antioxidant effects of polyphenols for cardiovascular health in humans is not established. J Nutr. 2011;141(5):989S-1009S. doi: 10.3945/jn.110.131490

43.Peterson JJ, Beecher GR, Bhagwat SA, Dwyera JT, Gebhardt SE, Haytowitz DB, et al. Flavanones in grapefruit, lemons, and limes: A compilation and review of the data from the analytical literature. J Food Compos Anal. 2006;19:S74-S80.

44.Yao LH, Jiang YM, Shi J, Tomás-Barberán FA, Datta N, Singanusong R, et al. Flavonoids in food and their health benefits. Plant Foods Hum Nutr 2004;59(3):113-122.

45.Vabeiryureilai M, Lalrinzuali K, Jagetia GC. Determination of antiinflammatory and analgesic activities of a citrus bioflavanoid, hesperidin in mice. Immunochemistry \& immunopathology. 2015;1:107. doi 10.4172/2469-9756.1000107

46.Peacock EE. Contraction. Peacock EE, editor. Wound Repair. 3rd Edition. Philadelphia:WB Saunders; 1984. 39-55. by Nigella Sativa in the deep dermal excision wound of mice whole body exposed to different doses of $\gamma$-radiation. Am Res J Med Surg. 2015;1(3):1-17.

48.Rudolph R, Vande Berg J, Schneider JA, Fisher JC, Poolman WL. Slowed growth of cultured fibroblasts from human radiation wounds. Plast Reconstr Surg. 1988;82(4):669-677.

49.Sonnemann KJ, Bement WM. Wound repair: toward understanding and integration of single-cell and multicellular wound responses. Annu Rev Cell Dev Biol. 2011;27:237-263. doi: 10.1146/annurevcellbio-092910-154251

50.Rumalla VK, Borah GL. Cytokines, Growth Factors, and Plastic Surgery. Plast Reconstr Surg. 2001;108(3):719-733.

51.Akmansu M, Unsal D, Bora H, Elbeg S, Influence of locoregional radiation treatment on tumor necrosis factor-alpha and interleukin- 6 in the serum of patients with head and neck cancer. Cytokine. 2005;31(1):4145

52.Gabbiani G, Hirschel BJ, Ryan GB, Statkov PR, Majno G. Granulation tissue as a contractile organism: A study of structure and function. J Exp Med. 1972;135(4):719-734.

53.Darby IA, Laverdet B, Bonté F, Desmoulière A. Fibroblasts and myofibroblasts in wound healing. Clin Cosmet Investig Dermatol. 2014;7:301-311. doi: 10.2147/CCID.S50046

54.Gorodetsky $\mathrm{R}$, McBride $\mathrm{WH}$, Withers HR. Assay of radiation effects in mouse skin as expressed by wound healing. Radiat Res. 1988;116(1):135-144.

55.Bumann J, Santo-Höltje L, Löffler H, Bamberg M, Rodemann HP. Radiation-induced alterations of the proliferation dynamics of human skin fibroblasts after repeated irradiation in the subtherapeutic dose range. Strahlenther Onkol. 1995;171(1):35-41.

56. Haubner F, Ohmann E, Pohl F, Strutz J, Gassner HG. Wound healing after radiation therapy: Review of the literature. Radiat Oncol. 2012;7:162. doi: 10.1186/1748-717X-7-162

57.Zelman D, Song IC, Porteous DD, Bromberg BE. The effect of total body irradiation on wound healing and hematopoietic system in mice. Bull N Y Acad Med. 1969;45(3):293-300.

58.Vegesna V, Withers HR, Holly FE, McBride WH. The effect of local and systemic irradiation on impairment of wound healing in mice. Radiat Res. 1993;135(3):431-433.

59.Lee MO, Song SH, Jung S, Hur S, Asahara T, Kim H, et al. Effect of ionizing radiation induced damage of endothelial progenitor cells in vascular regeneration. Arterioscler Thromb Vasc Biol. 2012;32(2):343-352. doi: 10.1161/ATVBAHA.111.237651

60.Jagetia GC, Rajanikant GK. Topical application of curcumin augments healing of deep dermal excision wound of mice exposed to whole-body gamma radiation. J Nur Healthcare. 2017;2(1).

61.Jagetia GC, Rajanikant GK. Role of curcumin, a naturally occurring phenolic compound of turmeric in accelerating the repair of excision wounds in mice whole-body exposed to various doses of $\gamma$-radiation. J Surg Res. 2004;120(1):127-138.

62.Jagetia GC, Rajanikant GK. Curcumin treatment enhances the repair and regeneration of wounds in mice hemi-body exposed to $\gamma$-radiation. Plast Reconstr Surg. 2005;115(2):515-528.

63.Song S, Cheng T. The effect of systemic and local irradiation on wound macrophage and repair promoting action of phenytoin sodium. Zhonghua Yi Xue Za Zhi. 1997;77(1):54-57.

64.Hasanoglu A, Ara C, Ozen S, Kali K, Senol M, Ertas E. Efficacy of micronized flavonoid fraction in healing of clean and infected wounds. Int J Angiol. 2001;10(1):41-44.

65.Zhou D, Brown SA, Yu T, Chen G, Barve S, Kang BC, et al. A high dose of ionizing radiation induces tissue-specific activation of nuclear factorkappaB in vivo. Radiat Res. 1999;151(6):703-709. 
Differential regulation of cytokines and transcription factors in liver by curcumin following hemorrhage/resuscitation. Shock. 2003;19(2):150156.

67.Hirata A, Murakami Y, Shoji M, Kadoma Y, Fujisawa S. Kinetics of radicalscavenging activity of hesperetin and hesperidin and their inhibitory activity on COX-2 expression. Anticancer Res. 2005;25(5):3367-3374.

68.Ghorbani A, Nazari M, Jeddi-Tehrani M, Zand H. The citrus flavonoid hesperidin induces p53 and inhibits NF- $\mathrm{B}$ activation in order to trigger apoptosis in NALM-6 cells: involvement of PPAR $\gamma$-dependent mechanism. Eur J Nutr. 2012;51(1):39-46. doi: 10.1007/s00394-0110187-2

69.Jagetia GC, Rajanikant GK. Curcumin stimulates the antioxidant mechanisms in mouse skin exposed to fractionated $\gamma$-irradiation. Antioxidants. 2015;4(1):25-41; doi:10.3390/antiox4010025

70.Elavarasan J, Velusamy P, Ganesan T, Ramakrishnan SK, Rajasekaran D, Periandavan K. Hesperidin-mediated expression of Nrf2 and upregulation of antioxidant status in senescent rat heart. J Pharm Pharmacol. 2012;64(10):1472-1482. doi: 10.1111/j.2042- 